Revista Tecné, Episteme y Didaxis: TED. Año 2014, Número Extraordinario. ISSN Impreso: 0121-3814, ISSN web: 2323-0126

Memorias, Sexto Congreso Internacional sobre Formación de Profesores de Ciencias. 08 al 10 de octubre de 2014, Bogotá

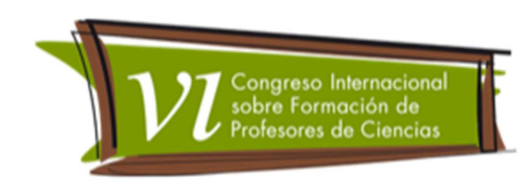

\title{
Cuestiones socio-ambientales en el desarrollo sostenible de fuentes energéticas; propuesta de educación científica intercultural en contextos rurales.
}

Medina Linares Luisa Fernanda'

Categoría 2. Trabajo de investigación (en proceso)

\section{Resumen}

Con la presente investigación se pretende analizar las implicaciones sociales, ambientales, científicas, económicas, culturales y didácticas, que suscita el uso de leña vs biogás como fuente de energía en contextos rurales, desde las llamadas cuestiones socio-ambientales; en la comunidad educativa Quiba Alta, ubicada en la Localidad Ciudad Bolívar. Este proyecto surge en el interés de fomentar una postura crítica en las decisiones que asisten a los seres sociales en la práctica, exaltando el aporte que desde la enseñanza de la química como ciencia intercultural se puede realizar en el empoderamiento de los estudiantes de sus costumbres en la formación ciudadana y para el desarrollo sostenible. Asimismo; en términos generales, se pretende examinar la pertinencia en el uso de cuestiones socio-ambientales como propuesta educativa para promover una educación científica intercultural en los sujetos involucrados.

\section{Palabras Clave}

Cuestiones Socio-Ambientales; Desarrollo Sostenible, ciencia intercultural, fuentes alternativas de energía.

Problema de investigación: ¿Cómo incide la cuestión socio-ambiental: "leña vs biogás" en el proceso de interculturización; científica, ciudadana y ambiental de los estudiantes del Colegio Rural Quiba Alta en el marco de educación para el desarrollo sostenible?

\section{Objetivos.}

General.

Analizar como inciden los debates generados a partir de la cuestión socio-ambiental "leña vs biogás" en el proceso de promoción y desarrollo de interculturalidad científica,

1 Universidad Pedagógica Nacional. luisamedina15@hotmail.com 
Revista Tecné, Episteme y Didaxis: TED. Año 2014, Número Extraordinario. ISSN Impreso: 0121-3814, ISSN web: 2323-0126

Memorias, Sexto Congreso Internacional sobre Formación de Profesores de Ciencias. 08 al 10 de octubre de 2014, Bogotá

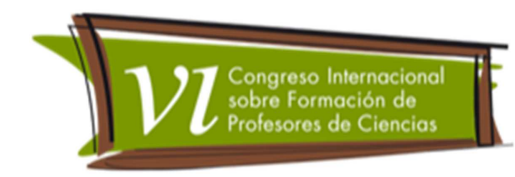

ciudadana, y ambiental por parte de los estudiantes del colegio Rural Quiba Alta en el marco de una educación para el desarrollo sostenible.

Específicos.

Diseñar e implementar desde las llamadas cuestiones-socio-ambientales, una secuencia didáctica, que favorezca el desarrollo y promoción de interculturalidad científica, ciudadana y ambiental en los estudiantes del colegio Rural Quiba Alta.

Caracterizar el estado inicial los estudiantes del colegio Rural Quiba Alta con respecto al grado de desarrollo de los aspectos interculturales, científicos y socio-ambientales; inherentes al uso de leña como combustible.

Evaluar la pertinencia en el uso de cuestiones socio-ambientales como estrategia para lograr una educación científica intercultural.

Examinar las implicaciones sociales, culturales, económicas y ambientales que suscita el uso del biodigestor, como propuesta de solución a una problemática local.

\section{Marco de Referencia}

\section{Componente Didáctico}

Con las llamadas cuestiones sociocientíficas se dilucidó de acuerdo con Pedretti, un "camino concreto en la enseñanza de las ciencias para conquistar los retos sugeridos por la educación CTSA" (2003, Martínez y Parga, 2013), estas cuestiones según Ratcliffe y Grace (2003; citados en Martínez, Parga y Aguilar, 2012) poseen en la mayoría de los casos, una base de conocimientos científicos de frontera, abarcan la formación de opiniones y la adopción de juicios personales y sociales de acuerdo con determinados valores; que en una sociedad diversificada como la que se vive actualmente, le permite al estudiante asumir posiciones sólidas respecto a las problemáticas ambientales y sociales; respondiendo, en términos generales a los problemas socioambientales que afectan a la humanidad (Rubba y Harkness; Rubba, SchonewegBradford y Harkness; Lederman; Acevedo (retomados por Merchán, 2011)). En efecto, resulta importante para la formación ciudadana de los estudiantes, comprender la ciencia como una actividad humana que presenta múltiples controversias e incertidumbres en su constitución y por tanto, requiere un análisis crítico de sus alcances e impactos (Martínez y Parga, 2013). La constitución de una ciudadanía 
Revista Tecné, Episteme y Didaxis: TED. Año 2014, Número Extraordinario. ISSN Impreso: 0121-3814, ISSN web: 2323-0126

Memorias, Sexto Congreso Internacional sobre Formación de Profesores de Ciencias. 08 al 10 de octubre de 2014, Bogotá

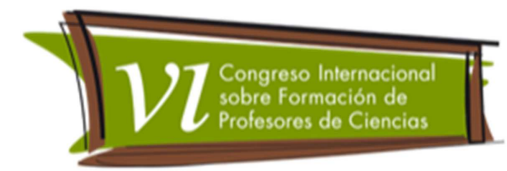

democrática con énfasis en temas polémicos relacionados con ciencia, tecnología y ambiente, requiere de una participación cívica en la toma de decisiones.

Según Sadler y Zeidler (2004; citados en Martínez, Parga y Aguilar, 2012) las cuestiones socio-científicas y socio-ambientales permiten no sólo asumir papeles propios de la comunidad científica, si no también asumir roles de los diferentes sujetos de la sociedad en general; por lo cual, los estudiantes proponen explicaciones de naturaleza diversa a los cuestionamientos que les permiten prepararse para enfrentar de manera crítica a múltiples problemáticas propias de la Enseñanza de las Ciencias.

En síntesis, la enseñanza de las ciencias centrada en el trabajo con cuestiones sociocientíficas y socio-ambientales en el aula, impulsa la participación de los estudiantes, asimismo favorece una educación abierta y crítica que contribuye con su formación ciudadana (Martínez y Parga, 2013); evidenciando que el futuro del conocimiento científico no puede ser apenas responsabilidad de científicos 0 gobiernos, siendo necesaria la participación de todos los ciudadanos en las discusiones sobre sus implicaciones sociales, éticas y ambientales. En consecuencia, Los problemas socio-ambientales pueden representar un contexto adecuado para llevar estos elementos a las aulas de ciencias y así contribuir a educar para la sostenibilidad (España y Prieto, 2009).

\section{Educación para el desarrollo sostenible}

El desarrollo sostenible según la Unesco, hace referencia a las relaciones entre las personas, y entre estas, y su medio ambiente. Está por tanto vinculado a los modelos de desarrollo social y económico, donde el elemento humano, como proceso social, es fundamental. Esta realidad, confiere a la educación para la sostenibilidad entendida como movimiento internacional de pensamiento y acción que promueve el respeto y cuidado de las personas, de la diversidad, el medio ambiente y de los recursos del planeta; una función estratégica, cuyo objetivo consiste en "integrar los valores inherentes al desarrollo sostenible en todas las facetas del aprendizaje con vistas a fomentar los cambios de comportamiento necesarios para lograr una sociedad más sostenible y justa para todos" (DESD y UNESCO; 2009).

\section{Interculturalidad}

Como concepto y práctica, la interculturalidad significa "entre culturas", pero no simplemente un trato entre culturas, sino un intercambio que se establece en términos y condiciones equitativas. Además de representar una meta por alcanzar, la interculturalidad debe ser entendida como un proceso permanente de relación, comunicación y formación entre personas, grupos, conocimientos, valores y tradiciones 
Revista Tecné, Episteme y Didaxis: TED. Año 2014, Número Extraordinario. ISSN Impreso: 0121-3814, ISSN web: 2323-0126

Memorias, Sexto Congreso Internacional sobre Formación de Profesores de Ciencias. 08 al 10 de octubre de 2014, Bogotá

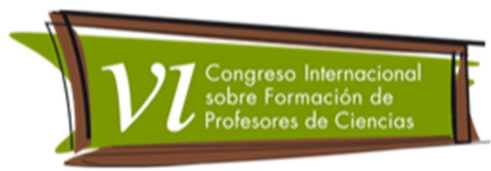

distintas; dirigida a propagar, construir, propiciar respeto mutuo y desarrollo pleno de las capacidades de los individuos, por encima de sus diferencias culturales y sociales. La interculturalidad no puede ser reducida a una simple mezcla, fusión o combinación híbrida de elementos, tradiciones, características o prácticas culturalmente diversas; más bien, ésta representa procesos dinámicos y de doble o múltiple dirección, repletos de creación y de tensión y siempre en construcción; procesos enraizados en las diferencias culturales reales y actuales. En consecuencia, el reto más grande de la interculturalidad consiste en, no silenciar las desigualdades, contradicciones y los conflictos de la sociedad o de los saberes y conocimientos sino trabajar con ellos y su posible intervención (Walsh, 2005). Por otra parte, una educación científica intercultural integra y se apropia de los principios de filosóficos y educativos de la alfabetización científica, promoviendo una postura crítica en decisiones críticas que tienen que ver con la ciencia, las situaciones humanas $\mathrm{O}$ el progreso social (Benarrochm,

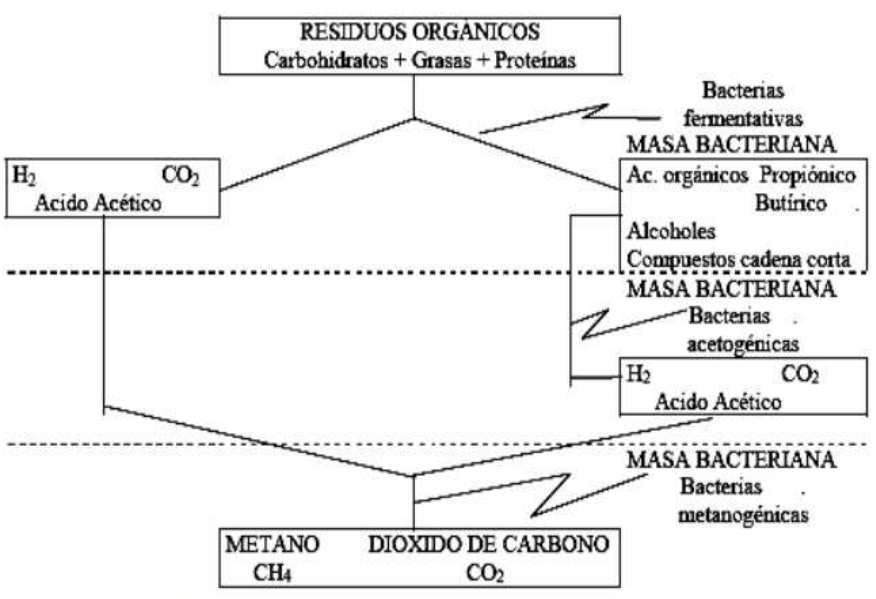

Figura 1. Síntesis de las etapas presentes en la digestión anaeróbica [Hilbert 2003].

Figura 1. Esquema biodigestor Tubular de plástico 2001).

\section{Componente disciplinar (Fundamentos teóricos del biogás).}

La digestión anaerobia que inicialmente se había empleado para satisfacer la demanda de energía (requerimiento de combustible); en los últimos años ha venidos demostrando su potencial para el tratamiento de los residuos y excretas de origen domésticos y agropecuarios, principales contaminantes del ambiente (Guevara, 1996). Este tratamiento de tipo anaerobio, es un proceso microbiológico en ausencia de oxigeno, en el que la biomasa (Cualquier tipo de materia orgánica que tiene su origen en un proceso biológico; esta puede ser de tipo natural, que corresponde a aquella que se produce espontáneamente en la naturaleza (Posso, 2002) y residual obtenida de las actividades agrícolas ganaderas y forestales (FAO, 2008)) se transforma por la acción microbiana, en biogás y bioabono; este proceso requiere una serie de reacciones bioquímicas generada por microorganismos, de los cuales una parte son 
Revista Tecné, Episteme y Didaxis: TED. Año 2014, Número Extraordinario. ISSN Impreso: 0121-3814, ISSN web: 2323-0126

Memorias, Sexto Congreso Internacional sobre Formación de Profesores de Ciencias. 08 al 10 de octubre de 2014, Bogotá

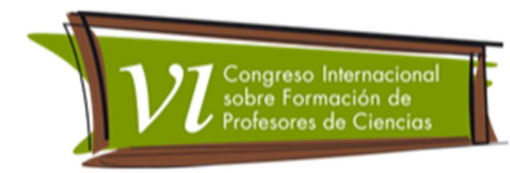

oxidados completamente por el carbono formando anhídrido carbónico o dióxido de carbono $\left(\mathrm{CO}_{2}\right)$, mientas otra es reducida en alto grado para formar metano $\left(\mathrm{CH}_{4}\right)$ (Guevara, 1996). Este tratamiento (como alternativa para aprovechar eficazmente el recurso biomàsico (Arboleda \& Salcedo, 2009)), ocurre en cuatro etapas; hidrólisis, acidogénesis acetanogénesis y metanogénesis (Ramón et al, 2006). El biogás que generalmente se produce en la digestión, es un gas incoloro, inflamable, con un poder calorífico de $4400 \mathrm{Kcal} / \mathrm{m}^{3}$ y un contenido de $60 \%$ de metano y $40 \%$ de dióxido de carbono, con aportes menores de nitrógeno, hidrogeno y gas sulfhídrico (Guzmán, 2008).

\section{Biodigestores.}

Los biodigestores conocidos también como plantas (productoras o de producción) de

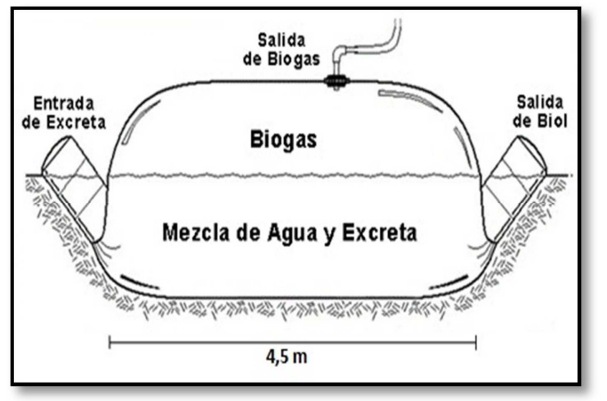
biogás, son recintos o tanques cerrados donde una mezcla de materia orgánica y agua permanecen un periodo de tiempo para lograr su descomposición produciendo biogás y bioabono (biol y biosol) (Ramón et al, 2006)

Figura 2. Síntesis de las etapas presentes en la digestión anaerobia propuesto por Hilbert, retomado en (Arboleda, 2009)

\section{Metodología}

Este proyecto se enmarca dentro de la línea de investigación Enseñanza de las Ciencias con enfoque Ciencia, Tecnología, sociedad y ambiente (CTSA) del grupo Alternaciencias de la Universidad Pedagógica Nacional, bajo un enfoque cualitativo de tipo etnográfico; dirigido a la comunidad educativa del Colegio Rural Quiba Alta, representada por los estudiantes que conforman el PRAE y describe la cultura, utilizando como estrategia metodología la observación participante.

En este orden de ideas, la presente investigación se desarrollará en cuatro momentos o fases diferenciadas 
Revista Tecné, Episteme y Didaxis: TED. Año 2014, Número Extraordinario. ISSN Impreso: 0121-3814, ISSN web: 2323-0126

Memorias, Sexto Congreso Internacional sobre Formación de Profesores de Ciencias. 08 al 10 de octubre de 2014, Bogotá

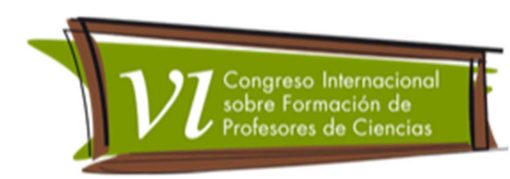

Esquema No1. Diseño Metodológico.

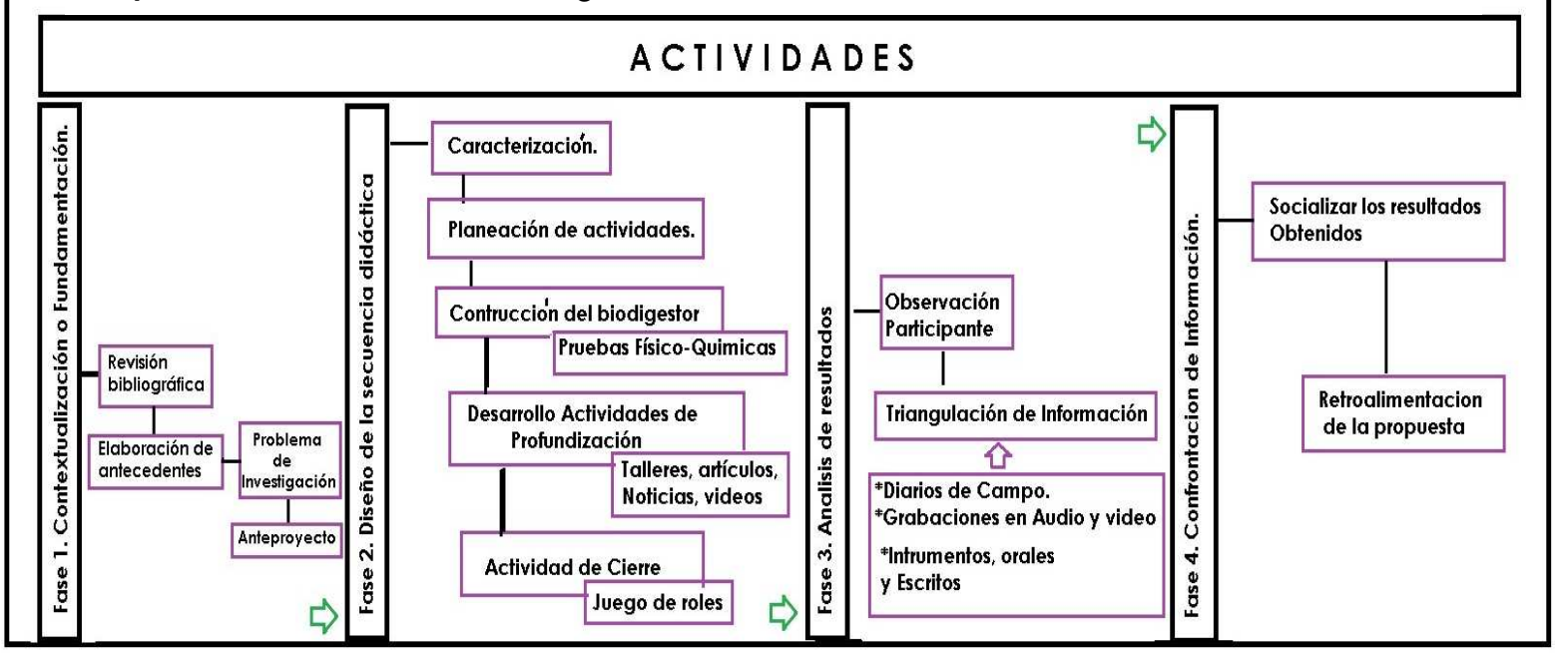

\section{Resultados Esperados.}

Con el desarrollo de esta propuesta; se espera en los estudiantes una postura crítica frente al uso de fuentes alternativas de energía, sustentado en el aporte de la química como ciencia intercultural, que posibilite un empoderamiento y apropiación de contenidos abordados en el proceso. Por otra parte se espera promover el uso de biodigestores artesanales como una propuesta favorable para generar alternativas de solución a una problemática local (acumulación de estiércol de cerdo en el suelo) basada en el uso de energías limpias y renovables.

\section{Referencias bibliográficas.}

Arboleda; Y \& Salcedo; L. (2009). Fundamentos para el diseño de Biodigestores. Modulo para la asignatura de construcciones agrícolas. Universidad Nacional de Colombia Sede Palmira.

Benarroch; A. (2001). Interculturalidad y enseñanza de las ciencias. Alambique, 29. Disponible en la página web http://www.academia.edu/3368337/Interculturalidad_y_ensenanza_de_las_cien cias.

DEDS \& UNESCO. (2009). Decenio de las Naciones Unidas de la Educación para el Desarrollo Sostenible (2005-2014). 
Revista Tecné, Episteme y Didaxis: TED. Año 2014, Número Extraordinario. ISSN Impreso: 0121-3814, ISSN web: 2323-0126

Memorias, Sexto Congreso Internacional sobre Formación de Profesores de Ciencias. 08 al 10 de octubre de 2014, Bogotá

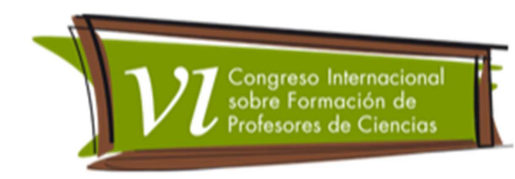

España; E \& Prieto; T. (2009). Educar para la sostenibilidad: el contexto de los problemas socio-científico. Revista Eureka sobre Enseñanza y Divulgación de las Ciencias, 6, (3), 345-354.

FAO. (2008). El estado mundial de la agricultura y la alimentación. Biocombustibles: perspectivas, riesgos y oportunidades. Roma.

Guevara; A. (1996). Fundamentos básicos para el diseño de biodigestores anaeróbicos rurales. Producción de gas y saneamiento de efluentes. Documento OPS/CEPIS/96. Centro panamericano de ingeniería sanitaria y ciencias del ambiente-Organización Panamericana de la salud, Lima, Perú.

Guzmán; C. (2008). Apuntes sobre consumo energético de biomasa. Diplomado en energía SNAP, proyecto No. 003/2008, PROLEÑA Soluciones energéticas Eficientes: La Paz, Bolivia.

Martínez; L \& Parga; D. (2013). La emergencia de las cuestiones sociocientíficas en el enfoque CTSA. Góndola, 8, (1), 23-35.

Martínez; L., Parga; D. \& Aguilar; D. (2012). Cuestiones sociocientíficas en la formación de profesores de ciencias. Revista EDUCYT, extraordinario, 139-151.

Merchán; N. (2011). Las cuestiones sociocientíficas: una alternativa de educación para la sostenibilidad. Documento recuperado el día 30 de Junio del 2014 de la página web http://lunazul.ucaldas.edu.co/index.php?option=content\&task=view\&id=608

Posso; F. (2002). Energía y ambiente: Pasado presente y futuro, Parte Dos: Sistema energético basado en energías alternativas. Geoenseñanza, 7, 54-73.

Ramón, A., Romero, F. \& Simaca, L. (2006). Diseño de un biodigestor de canecas en serie para obtener gas metano y fertilizantes a partir de la fermentación de excrementos de cerdo. Revista Ambiental: Aire, Agua y suelo, 1, 15-23.

Walsh; C. (2005). La interculturización de la educación. Ministerio de educación, Lima Perú. 